\title{
Consumer-Directed Health Care: Can Consumers Look After Themselves?
}

\author{
Daniel McFadden, ${ }^{a}$ Joachim Winter, ${ }^{b}$ and Florian Heiss ${ }^{c}$
}

JEL-Classification: C25, C61, C81, D12, D91, H51, I10, I12, I18

Keywords: prescription drugs, health insurance, Medicare Part D

\section{Introduction}

In health care systems today, including those of Switzerland and the United States, participants do not necessarily see the big picture of lifetime health costs and quality of life, and in many systems consumers and providers lack the incentives to manage preventative and chronic care to maximize lifetime welfare. Resource allocation problems induced by asymmetric information and misaligned incentives are exacerbated if consumers fail to have the acuity or perspective needed to make decisions consistent with their self-interest when faced with complex health care choices with ambiguous, hard-to-anticipate future consequences. This paper examines rationality of consumers' health perceptions and choices using as a natural experiment the recent introduction in the United States of a highly subsidized market for prescription drug insurance, and draws lessons from this experiment on the practicality of "Consumer Directed Health Care" as an approach to achieving efficient allocation of health care resources by confronting consumers with the full marginal costs of the services they use.

Section 2 outlines the worldwide health care crisis, and the policy problems it poses. Section 3 describes Consumer Directed Health Care (CDHC). Section 4 describes a new subsidized market for prescription drug coverage organized for seniors in the United States, Medicare Part D. Section 5 summarizes consumers' behavioral response to this market. Section 6 gives conclusions, including

a Department of Economics, University of California, Berkeley, CA 94720-3880, mcfadden@ econ.berkeley.edu. This research was supported by the National Institute of Aging, Behavioral and Social Research. All opinions are solely those of the authors.

b Department of Economics, University of Munich, joachim.winter@lrz.uni-muenchen.de.

c Department of Economics, University of Munich, florian.heiss@lrz.uni-muenchen.de. 
the lessons to be drawn from this new market for the potential of CDHC as an approach to rationalizing health care resource allocation.

\section{The World Crisis in Health Care}

The financing and delivery of effective health care is a significant problem around the world. In most developed nations, access to adequate health care is viewed as a fundamental right of the citizenry, and an obligation of government. Rising health care costs are stressing its financing, and adding to the burden on governments to manage health care insurance and delivery systems, and assure access. Even in countries such as Switzerland and the United States that emphasize individual responsibility and market solutions to resource allocation, government financing is an important component of total spending on health care, and government regulation is required to control adverse selection, guarantee access, and keep costs in check. Figure 1 shows total spending in 2005 on health care as a proportion of GDP, and the proportion of health care that is publically financed, in the twenty developed countries with the highest per capita GDP. At least one-third of health is government-financed in every developed country, giving government a direct role in every health care delivery system. The United States has the most expensive system (15.4 percent of GDP) and one of the lowest rates of public financing (44.7 percent of health spending). Switzerland is second (11.5 percent of GDP with public financing of 58.5 percent of health spending). International comparisons of health statistics require caution, due to differences in accounting systems, health service pricing, population behavior (e.g., smoking), and health care priorities. With this reservation, the data in Figure 1 support the hypothesis that total health care spending as a proportion of GDP is not causally linked to the share of health care that is publically funded. In particular, the two countries with the lowest public financing of health care, Singapore and the United States, are at the low and high extremes, respectively, of developed country health care cost as a percent of GDP.

Health care problems are going to get much worse in the future, placing added stress on health care finance, and an added burden of assuring access for the poor. Real health care costs per capita in the United States have grown since 1980 at a 4.4 percent annual rate, and this rate is expected to accelerate in the future, with some projections that health expenditures in the United States will reach 40 percent of GDP by 2050. Other developed countries start from a lower base, but are likely to experience comparable growth rates in real health care costs. 
Figure 1: Health Care Financing, Developed Countries, 2005

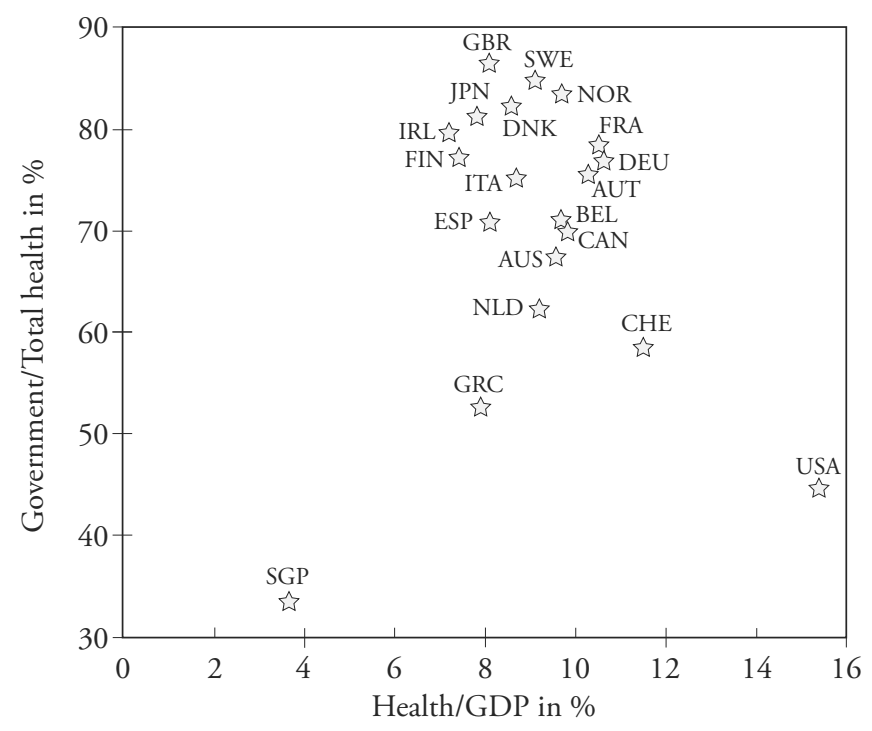

Source: WHO, World Health Statistics, 2007

Countries: Norway (NOR), United States (USA), Ireland (IRL), Switzerland (CHE), Netherlands (NLD), Austria (AUT), Australia (AUS), Canada (CAN), Denmark (DNK), Belgium (BEL), United Kingdom (GBR), Sweden (SWE), Singapore (SGP), Germany (DEU), Finland (FIN), Japan (JPN), France (FRA), Italy (ITA), Greece (GRC), Spain (ESP)

There are a number of reasons for this gathering storm. First, populations are getting older, and the old require more medical maintenance. More than a third of all medical costs are incurred in the last 18 months of life, and are only marginally effective in improving quality of life. Second, incomes are rising, and staying alive is the ultimate luxury good. The elasticity of total health costs with respect to income, estimated from WHO cross-section data for the 80 countries with the highest GDP per capita in 2005, is 1.24. Third, most health care systems rely on some form of "cost-plus" reimbursement of providers, which rewards high-cost "life-saving" innovations, such as dialysis, MRI's, transplants, stents, and biotechnology, and discourages "cost-saving" innovations. ${ }^{1}$ New medical technologies

1 If insurers or the government reimburse providers at a fixed markup over cost, then the provider makes more money prescribing an expensive therapy, and less money prescribing an inexpensive one. If instead reimbursement is based on the cost of a standardized therapy, providers lose money by prescribing more expensive therapies, even if they are better for the patient, and providers may reject patients who require unprofitable therapies. 
can lengthen and improve the quality of life, but they also become "hammers in search of nails" that increase medical costs. The full economic costs of health care are often not visible to consumers or providers, and the incentives that most systems give consumers, providers, and insurers do not force hard choices.

Broadly speaking, more health care spending produces better health. Figure 2 plots life expectancy against health spending per capita (converted to dollars based on Purchasing Power Parity) in 144 countries, and Figure 3 details this relationship for the twenty countries with the highest GDP per capita. These figures indicate that life expectancy increases at a decreasing rate with health spending, although some countries fall well below the frontier. In the twenty developed countries where health spending is high, any effect of spending on life expectancy is lost in the noise from country-specific factors. The United States is dead last among the developed countries in life expectancy, even though it has the highest health spending per capita.

Figure 2: Life Expectancy at Birth, 2005

144 Countries with Populations > 1 Million

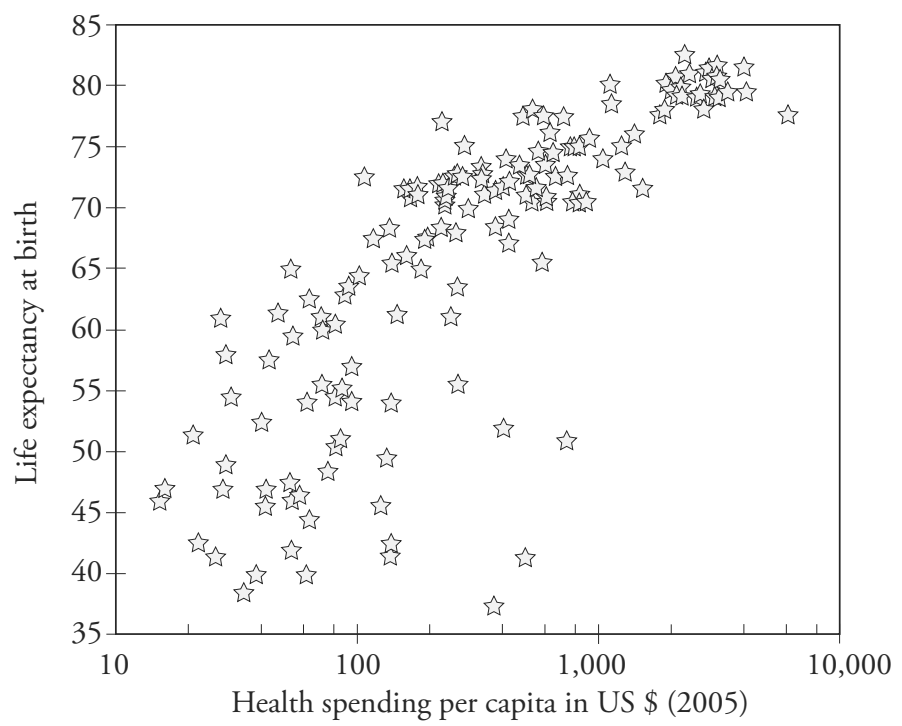

Source: WHO, World Health Statistics, 2007 
Figure 3: Life Expectancy at Birth, 2005

20 Developed Countries with Highest GDP/Capita

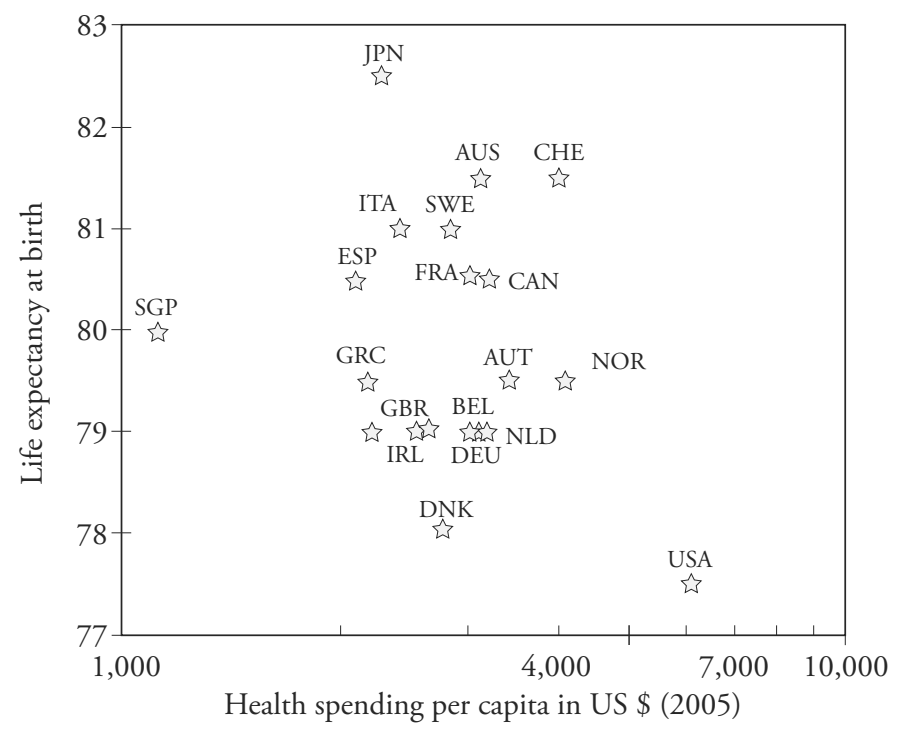

Source: WHO, World Health Statistics, 2007

A revealing measure of the success of a health care system in preventing and treating disease is the age 15 to 60 survival rate, since keeping workers and parents alive is a social and economic priority in most places. ${ }^{2}$ Figure 4 plots this survival rate against per capita spending on health care for 144 countries. The elasticity of the survival rate with respect to spending is 0.111 ( $\mathrm{SE}=0.014$ ), showing a significant upward trend, but also sharply decreasing returns to increased spending. Given spending level, the countries with the best age 15-60 survival rate performance are Cuba, Singapore, and Georgia, and the countries with the worst performance are Botswana, Swaziland, South Africa, Namibia, Zimbabwe, Zambia, Uganda, Gabon, and the United States. This pattern suggests that easy access to inexpensive primary care is a critical factor for reducing mortality among working-age people.

2 This index omits the influence of infant mortality, which is often linked to poverty, and the influence of cultural and medical choices on treatment of the elderly. 
Figure 4: 2005 Survival Probability from Ages 15 to 60

144 Countries with Populations $>1$ Million

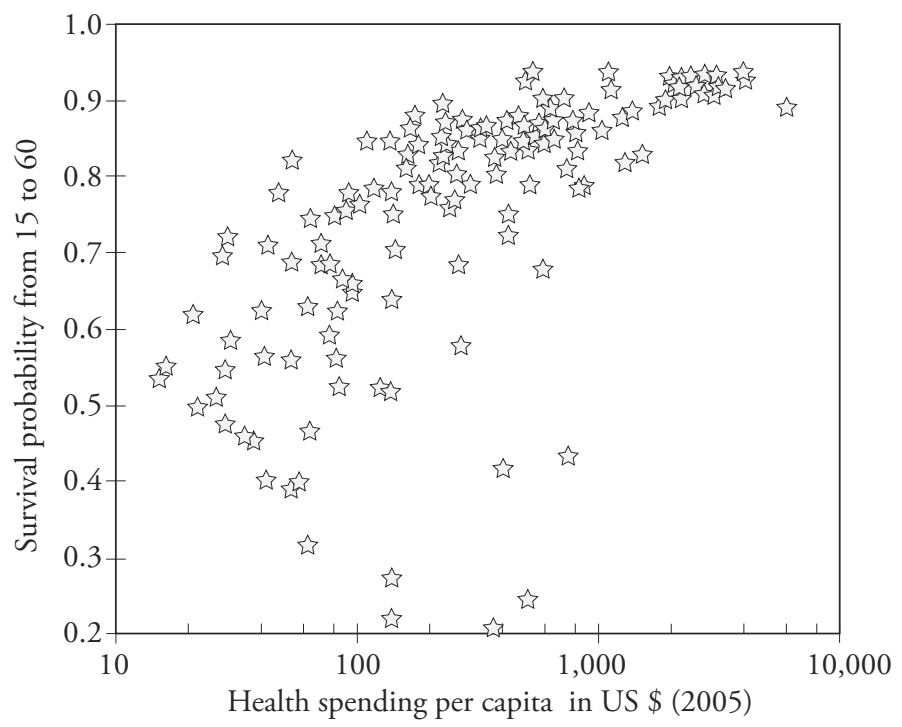

Source: WHO, World Health Statistics, 2007

Figure 5 looks more narrowly at age 15-60 survival rates in the twenty countries with the highest GDP per capita. In this figure, Switzerland performs well, with one of the highest survival rates overall, albeit at higher cost than competitors like Sweden and Singapore. The United States performs particularly poorly. There is no significant association of survival rates and health spending in these developed countries, whether or not the United States and Singapore are omitted as outliers. ${ }^{3}$ Possible explanations for this lack of association are the omission of important behavioral factors (e.g., smoking), increased prices of health services induced when demand increases and there are bottlenecks in supply, inefficient use of expensive medical technologies and treatments rather than inexpensive preventative care, allocation of most incremental spending to the very young and very old, and purchase of services that increase quality of life, but are not reflected

3 Singapore has a largely private universal health care system that achieves excellent health outcomes, with health care delivery and prices actively regulated to keep costs far below international norms. 
in measured health outcomes. All of these may contribute to the poor performance of the United States, but the most likely explanation for its performance is uneven health care access for working-age people, particularly a lack of programs to promote preventative care and to monitor chronic care. Detailed studies of detection and treatment of specific conditions in the United States and other countries indicate that the United States often has among the best outcomes for acute care, but lags behind badly in preventative care and treatment of chronic conditions. Switzerland and Singapore demonstrate that with effective management of health care markets, a relatively low proportion of public spending is not a barrier to good health outcomes.

Figure 5: 2005 Survival Probability from Ages 15 to 60

20 Developed Countries with Highest GDP/Capita

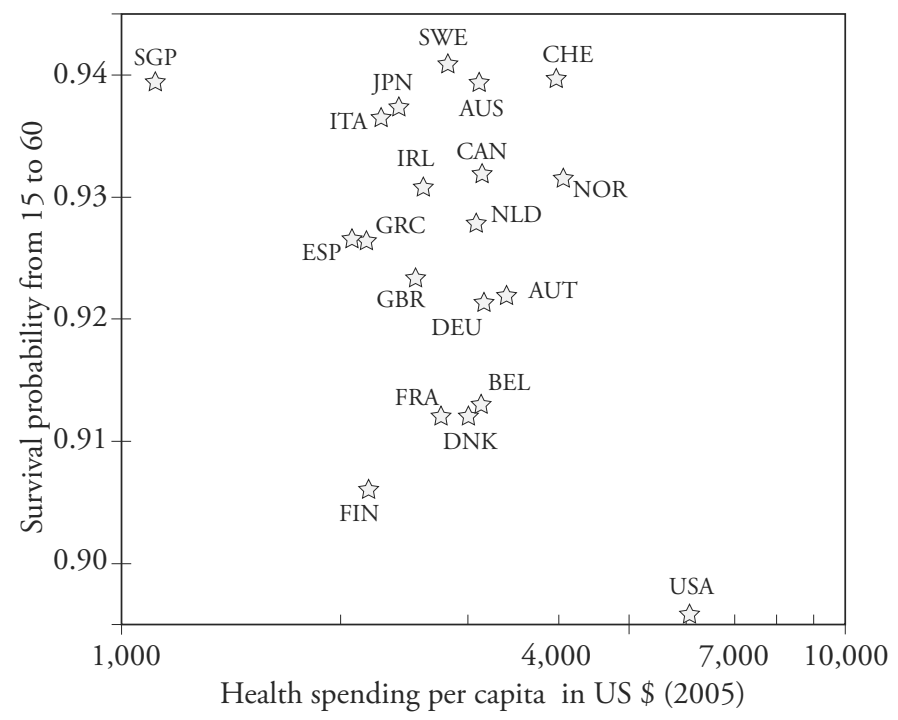

Source: WHO, World Health Statistics, 2007

Most developed countries have mixed "universal coverage" systems with mandated health insurance financed from some combination of consumer, employer, and government sources, and health services delivered by some combination of government and government-chartered organizations and private providers. 
Consumer co-payments for service, and private supplemental insurance for coverage gaps, are common. Switzerland's system is of this mixed form, with mostly private providers. The United States is the only developed country without universal coverage for working-age people, but it does provide universal coverage for the elderly (Medicare) and people in poverty (Medicaid).

The challenge to policy-makers is to modify current health care systems to manage costs and control cost increases without compromising the quality of health care. Some economic aspects of the crisis are important in considering policy alternatives. First, financing of health care through general government revenues or mandated employer contributions introduces deadweight losses to an economy due to the incentive effects of taxes and mandates, and these will become more severe as the health care component of GDP rises. Second, the income redistribution required to achieve universal health care rises with health care costs, and with the dependency ratio of non-workers to workers, requiring an increasing degree of social commitment and political will from the populace. Third, tight government regulation to control costs by capitation of payments to providers, or regulating medical innovation and use of expensive new therapies, requires a great deal of information and careful management, and even if done well will almost certainly be viewed as limiting individual choice. Fourth, the advantages of competition among insurers and providers in constraining costs and providing price signals for value are tempered by problems of agency, adverse selection, and moral hazard. Agency issues arise between consumers and providers, between providers and insurers, and between consumers and insurers. Consumers typically have private information on their health and tastes, providers have private information on possible diagnoses and therapies, and neither of these parties or third-party insurers can easily obtain and verify the information available to other market participants. It is very difficult to organize private markets and align incentives to avoid adverse selection, where provider and insurer agents use observable information to screen customers and select the most profitable, and moral hazard, where therapy choices are made in response to incentives that are not aligned with the full marginal costs of alternatives. Fifth, the social objective of pooling health risks is fundamentally inconsistent with an objective of presenting consumers with the full marginal costs of alternatives so that rational response can be used to induce efficient prices and resource allocation. Sixth, consumers may fail to have the acuity needed to make health care choices consistent with their self-interest, particularly when both consumers and their provider-agents lack the information and perspective needed to see the big picture of lifetime health costs, and the incentive to manage preventative and chronic care to minimize lifetime private and social costs of health problems. 


\section{Consumer-Directed Health Care}

Consumer-Directed Health Care (CDHC) is being promoted in many countries as a way to keep health costs in check while satisfying consumers' health care needs. CDHC refers to a variety of schemes in which consumers manage and pay for their own care, and have access to the information on prices and qualities needed to make informed choices among providers and therapies. CDHC plans usually combine high-deductible health insurance with a consumer-funded tax-preferred savings account (HSA) or employer-funded Health Reimbursement Account (HRA) that is used to pay for routine health care expenses and can be rolled over or recovered for other expenses if not used for health care. The plans may include government subsidies for low-income consumers. BEEUw KES Buntin et al. (2005) note that CDHC designs are "predicated on the assumption that consumers will seek and use information on the efficacy of treatment and provider performance if they have a sizeable financial stake in care decisions".

The potential benefits of CDHC plans for consumers would be realized if they adjust their choices in favor of more cost-effective providers and therapies, and their "voting with their feet" induces cost-saving competition among providers. HeRrick (2005) suggests some of the mechanisms that consumers under a CDHC plan might use to achieve cost economies:

- Use the Internet to freely browse medical journals and libraries for information.

- Test children for ear or strep infections at home using over-the-counter do-ityourself diagnostic kits.

- E-mail personal physicians to obtain a diagnosis, rather than making an inoffice visit.

- Use the Internet to have test results evaluated or obtain a second opinion from a Web-based physician.

- Patients with chronic diseases can manage their conditions and control their health care. For example, patients with diabetes can be trained to inject insulin, monitor and maintain a log of blood glucose levels, and use the results to adjust their dietary intake, activity levels and medicine doses.

This list illustrates how consumers facing full prices of medical alternatives might manage their demand to control their costs, but also illustrates the potential risk of CDHC: self-diagnosis by a patient is likely to be less informed and more variable in health outcomes than a careful diagnosis by an expert provider. Of course, decisions by principals on whether to retain expert agents or risk self-management 
are present in all current health care systems, and in many other aspects of life, so that the issue of poor self-diagnosis decisions in CDHC is a matter of degree. However, the relatively high marginal cost of consulting an expert provider in $\mathrm{CDHC}$ brings into focus the deeper behavioral question of how rational consumers will be when making medical choices. The cognitive tasks that seem to challenge rationality the most are those that require weighing unlikely but momentous events in the distant future whose links to current decisions are ambiguous, and many health care choices fit this description; see McFAdDEN (2006). Davis (2004) cites studies indicating that many consumers respond to increased marginal costs of health care by foregoing health care. This is of course the rational response if low co-payments in conventional health care delivery systems induce excessive use of health services, but Davis argues that more commonly the CDHC demand response reduces consumer welfare by increasing future health problems and costs. A study by Joyce et al. (2002) finds, for example, that increased co-payments for two drugs, statins for high cholesterol and anti-hypertensives for high blood pressure, reduce use and result in higher lifetime medical costs, in addition to the welfare costs to consumers of adverse medical events. These findings are consistent with the broader behavioral observation that consumers discount future risks too strongly to be lifetime optimizers. Some CDHC plans offset behavioral deficiencies in consumer choice for preventative and chronic care by reducing the marginal costs of these services to encourage optimal utilization. This is likely to be an important element in acceptable CDHC plans.

Consumer acuity failures do not necessarily mean all the benefits of CDHC are lost, but do mean that more careful market management is likely to be required to realize the benefits. First, consumers are heterogeneous, and if a substantial majority are rational, their behavior may be sufficient so that demand signals and price response lead to relatively efficient pricing of health resources. A minority of "noise" consumers will be at risk to themselves, a problem that may require paternalistic intervention for their welfare, and regulation of opportunistic suppliers, but may not be a risk to the market determination of efficient prices. Second, consumers may be better decision-makers when they have good information, clearly described alternatives, acceptable defaults, and training. These aspects of market operation can be built into its design. For example, a reform as simple as requiring providers to have posted price lists, web sites that provide comparative prices and quality ratings, and defaults that look for low costs might be enough to induce effective demand response. For diagnostic and preventative care, services that pay their own way in terms of reduced hospitalization costs in the future (e.g., pre-natal care, statins) could be made "opt out" rather than "opt in", so that an active decision, and perhaps even a financial penalty, is required 
to refuse these services. Second, CDHC is not necessarily wedded to private market provision of health care services. While a motivation for $\mathrm{CDHC}$ is that it will induce demand signals to guide private providers and determine prices, it could also be used to motivate providers and provide internal prices in a unitary "single provider" system. In the future when health care looms large in the GDP of a nation, it may be as important to use some form of CDHC to guide health resource allocation in "single provider" systems as it is to control costs in systems organized around markets with private providers.

\section{An American Experiment With CDHC}

Before 2006, roughly 25 percent of the elderly aged 65+ in the United States had little or no insurance coverage for their prescription drugs, and 10 percent had annual pharmacy bills exceeding $\$ 5,600$. Given that 2005 median per capita income in this population was $\$ 15,700$, and that 29 percent of this population had incomes below $\$ 10,000$, uninsured prescription drug costs were a heavy burden on unhealthy elderly. ${ }^{4}$ A new social insurance program, Medicare Part D, was introduced in 2006 that provides access to standardized, heavily subsidized, prescription drug coverage through Medicare-approved plans sponsored by private insurance companies and HMOs. This new program relies on consumer behavior and competition among insurers to attain satisfactory market outcomes with limited government regulation; see BACH and McClellan $(2005,2006)$.

Figure 6 shows beneficiary out-of-pocket costs, excluding premium, under the 2006 Part D standard coverage benefit schedule. The plan covered 75 percent of drug costs between a deductible of $\$ 250$ and a ceiling of $\$ 2,250$, and covered 95 percent of drug costs above a catastrophic threshold of $\$ 5,100$, which corresponds to a beneficiary true out-of-pocket (TrOOP) cost of $\$ 3,600$. Between the $\$ 2,250$ ceiling and the $\$ 5,100$ threshold, there is a gap in which the consumer pays all drug costs. The national average base premium for the Standard plan was $\$ 32.20$ in 2006. Insurers could offer approved, unsubsidized supplemental plans to cover the gap. The inflection points in the benefit schedule are scaled in each subsequent year by a prescription drug price index, and premiums are determined in the market.

4 Source: U.S. Census Bureau, Current Population Survey, 2006 Annual Social and Economic Supplement.

5 In 2007 and 2008, respectively, the deductible rose to $\$ 265$ and $\$ 275$, the gap threshold rose to $\$ 2,400$ and $\$ 2,510$, and the catastrophic coverage threshold rose to $\$ 3,850$ and $\$ 4,050$, and the national average premium changed to $\$ 27.35$ and $\$ 27.93$. 
Figure 6: Part D Standard Plan Out-Of-Pocket Costs, 2006

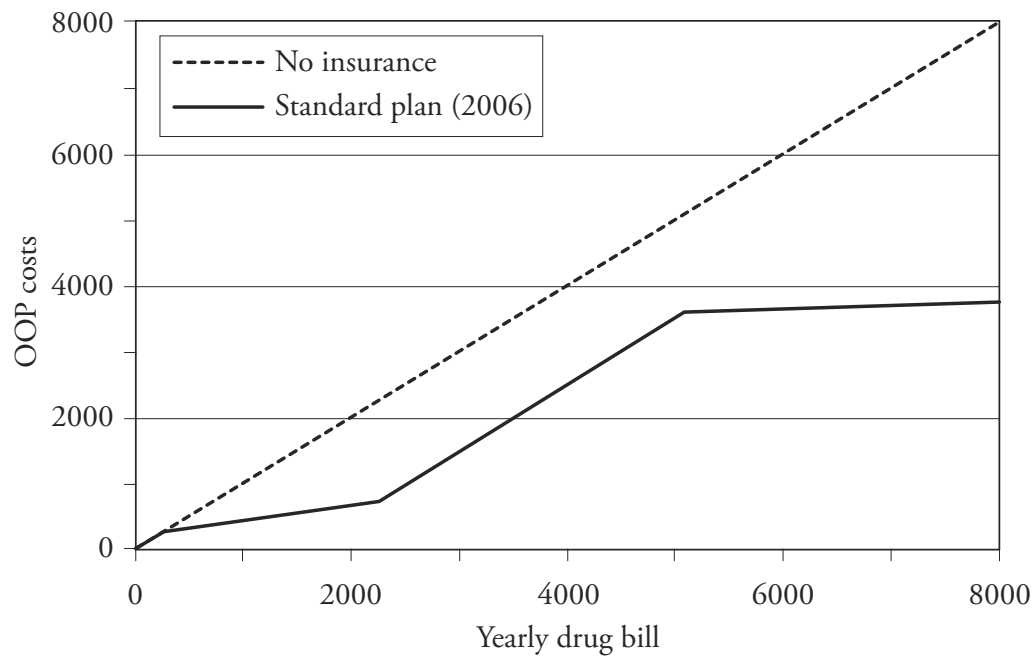

The design of the government subsidy of the Part D market has an important influence on the plans available to consumers and their premiums. Plan sponsors receive a direct subsidy, a capitated payment that on average covers 74.5 percent of their net standard plan benefits paid plus overhead. In addition, the government reinsures 80 percent of drug bills in the catastrophic region. Insurers submit bids to the government that equal their expected net benefit costs for a beneficiary of average health, plus their target overhead. The government gives a sponsor a direct subsidy equal to 74.5 percent of the national average bid, and then sets each sponsor's premium to cover its bid net of the subsidy. The result of this calculation is that an increased bid from a sponsor is passed through, dollar for dollar, into an increased premium. The direct subsidy is adjusted by risk-weighting, based on the health measured by the "Rx Hierarchical Condition Category" (RxHCC) of each of the sponsor's enrollees, to neutralize the effects of selection. ${ }^{6}$ A further adjustment pays the premiums for low income enrollees. Plan design is tightly regulated, but insurers have some control over their formularies and

6 A summary of the Part D system for bidding, premiums, and subsidies is given in MedpaC (2006). Details of the risk-adjustment weighting are given in RoBst, Levy, and IngBer (2007). 
co-payment arrangements, and can offer extended coverage features for additional premiums. Coverage extensions are not subsidized. Competition between sponsors for enrollees is expected to limit bids and drive premiums down to levels that achieve normal profit for sponsors. Negotiations between sponsors and pharmaceutical companies to determine stated drug prices are essentially unregulated, under the theory that competition among sponsors and therapies will induce efficient drug pricing. However, drug pricing under this market design creates a substantial problem in achieving Part D market efficiency, as pharmaceutical companies can increase profits by increasing stated drug prices and offsetting these increases with rebates (kickbacks) to sponsors, leaving sponsors at least as well off and able to offer lower premiums, but the government and beneficiaries on average worse off because of increased gap and reinsurance costs.

\section{Consumers' Behavioral Response To The Part D Market}

We summarize findings on consumer behavior in the Part D market presented in Winter et al. (2006) and Heiss, McFadden, and Winter (2006, 2007). The questions addressed in these studies are consumer information and attitudes toward this market, consumer market behavior, and the implications of this behavior for the stability and efficiency of this market, and the welfare of consumers.

Enrollment in a Part D plan is open to any Medicare beneficiary, which includes most Americans over age 64. Enrollment is voluntary, but consumers who fail to enroll upon becoming eligible face a penalty of one percent of the national average premium for each month of delay in enrolling. In addition to choosing whether to enroll, consumers had to time their enrollment in the first, extended open enrollment period in early 2006, choose an insurer and plan (e.g., standard or extended coverage), and choose whether to switch plans in subsequent annual open enrollment periods at the end of each calendar year.

Data. To study consumers in the Part D market, we designed an internet panel survey of older Americans, termed the Retirement Perspectives Survey (RPS). This panel was drawn from a random sample of the population, and was administered by a private survey research firm, Knowledge Networks. The first wave of the panel was conducted in November 2005, just before the start of the initial Part D open enrollment period, and included 4738 individuals aged 50 and over. The second wave was conducted in May 2006, immediately following the end of the initial open enrollment period, and included 2137 individuals aged 65 and over. A final wave was conducted in February 2007, following the close 
of the second open enrollment period, and included 2711 individuals aged 65 and over, including a number of people who were missing from the May 2006 wave. In this panel, a core of 1569 individuals had complete data in all three waves, and of these 443 were active deciders, people who were not automatically enrolled by virtue of being on an employers' health plan, on Medicaid, or in a Medicare-Advantage plan offered by a health maintenance organization (HMO) that provided comprehensive medical care including prescription drugs. These active deciders had free, effectively unguided choices on enrollment and plan, so their behavior provides the best evidence on the ability of consumers to handle CDHC choice situations.

Consumer Information and Satisfaction. At the start of the initial enrollment period for Part D in November 2005, many eligible consumers were poorly informed about the new Part D market. A substantial minority, 39.5\%, had little or no knowledge about Part D. Lack of information was severe among those with low SES, in bad health (poor or fair self-rated health status) or with low cognition, and those who combined low SES, bad health, and low cognition were particularly at risk, with $54.3 \%$ having little or no knowledge. Initially, consumers found the program complex, and were particularly dissatisfied with formularies and the coverage gap. Consumer knowledge and satisfaction have improved over time, but a significant minority remain dissatisfied with the program (PERRY et al., 2006; KRC RESEARCH, 2007), with problems centered on the gap, formularies, and the appeals process when claims are rejected.

Enrollment. Table 1, adapted from Heiss et al. (2007), breaks down the total age $65+$ Medicare population by socioeconomic status and level of drug use prior to introduction of the Part D program, and gives the rate of non-enrollment (in Part $\mathrm{D}$ or other comparable programs) by category. Overall, the enrollment rate was high, 93.6 percent of this eligible population. Non-enrollment was concentrated among healthy people with little prior drug use, and was highest among people who were healthy, low income, and less educated. Automatic enrollment for 71.8 percent of the population who were on employer health plans or on welfare (Medicaid) contributed to the overall high enrollment rate. Among active deciders, the enrollment rate was only 78.3 percent. Enrollment was myopically optimal, yielding positive expected benefits net of premium, for 81.7 percent of the population, and 8.4 percent of the population was myopically irrational, failing to enroll in the face of positive expected net benefits. We found that people with high pharmacy bills who could benefit immediately from the program mostly enrolled early, while those with low pharmacy bills for whom Part D had only insurance and option value enrolled late in the initial open enrollment period. 
Table 1: Size of Enrolled Subpopulations Classified by Socioeconomic Status and 2005 Prescription Drug Use

\begin{tabular}{l|r|rrr}
\hline & \multicolumn{4}{c}{ Prescriptions, Nov. 2005 } \\
& Total & \multicolumn{1}{c}{0} & $1-2$ & $3+$ \\
\hline Total Medicare population (mil) & 35.8 & 3.7 & 9.1 & 23.0 \\
$\quad$ Percent uncovered & 7.4 & 18.5 & 8.5 & 5.2 \\
\hline Income \$20K or more (mil) & 24.9 & 2.7 & 7.0 & 15.3 \\
$\quad$ Percent uncovered & 7.3 & 11.1 & 8.5 & 6.1 \\
Income less than \$20K (mil) & 10.9 & 1.0 & 2.1 & 7.8 \\
$\quad$ Percent uncovered & 7.6 & 38.2 & 8.5 & 3.3 \\
\hline More than High School (mil) & 13.5 & 1.7 & 3.7 & 8.1 \\
$\quad$ Percent uncovered & 6.6 & 13.3 & 6.5 & 5.2 \\
No More than High School (mil) & 22.4 & 2.0 & 5.4 & 14.9 \\
$\quad$ Percent uncovered & 7.9 & 22.8 & 9.9 & 5.2 \\
\hline Income less than \$20K \& High School or less (mil) & 7.8 & 0.7 & 1.4 & 5.7 \\
$\quad$ Percent uncovered & 7.8 & 39.6 & 10.2 & 3.2 \\
\hline
\end{tabular}

Source: Retirement Perspective Survey, 2005 and 2006; weighted using KN sample weights and adjusted to match CMS population-level enrollment data.

Choice of Sponsor and Plan. Part D enrollees had a choice of sponsor and plan type. Sponsors varied from State to State, with about 50 alternatives in most States. A number of national plans were offered in all State markets. Plans offered included the Standard plan specified by the government, actuarially equivalent plans that varied the deductible and/or co-payment arrangements, and extended plans that offered coverage in the gap for either generic drugs only, or both generic and branded drugs. Sponsors varied in their plan premiums, formularies, and placement of drugs in co-payment tiers. Extended plans with gap coverage were limited in availability in 2006, but for generic gap coverage became more widely available in 2007 and 2008. Extended plans that cover both generic and branded drugs were initially limited in availability, and by 2008 were almost entirely gone from the market. Plan premiums initially varied widely across sponsors, but their range has narrowed with experience. Standard and equivalent plan premiums have maintained stable premiums on average, with sharp increases in the premiums for plans that were initially the cheapest. The premiums for extended plans with generic gap coverage have increased sharply over time. Table 2 gives the distribution of RPS enrollee choices among plan types, and the average premiums they paid. 
Table 2: Types of Plans Chosen by RPS Enrollees

\begin{tabular}{lcc|cc}
\hline & \multicolumn{2}{c|}{ Share (\%) } & \multicolumn{2}{c}{ Average Premium $(\$ / \mathrm{mo})$} \\
& 2006 & 2007 & 2006 & 2007 \\
\hline Standard plan & 36.3 & 26.2 & 17.0 & 17.8 \\
Equivalent plan & 54.3 & 59.9 & 26.6 & 28.0 \\
Generic Gap Coverage & 4.8 & 13.2 & 46.1 & 56.5 \\
Full Gap Coverage & 4.6 & 0.6 & 60.8 & 102.8 \\
\hline Total & 100.0 & 100.0 & 25.6 & 29.6 \\
\hline
\end{tabular}

Overall, we find that observed plan pricing is consistent with calculated breakeven premiums for sponsors; see Heiss et al. (2007), Table 13. In 2006, the actuarial value of deductible coverage was $\$ 13$ per month, and the actuarial value of generic gap coverage (with flexible capitation which delays the onset of catastrophic coverage until the beneficiary's TrOOP reaches $\$ 3,600$ ) was $\$ 11.32$ per month, absent adverse selection, somewhat higher than the observed average price increments. Consumers gravitated to sponsors with low premiums, and to plans without extended features. Adverse selection appears to be affecting the offering of (unsubsidized) extensions to the Standard plan: Full gap coverage plans had become essentially extinct in 2008, and generic gap coverage plans appear to be attracting primarily heavy drug users, and have increased premiums to levels that nearly price them out of the market.

Risk Perception and Dynamic Optimization. Part D enrollment and plan choices have consequences that depend on the future health and prescription drug needs of the decision-maker. Thus, a rational consumer must consider not only intertemporal preferences and attitudes toward risk, but also the probabilities of alternative future life courses. Two aspects of Part D decisions require the consumer to be forward-looking. First, in the enrollment choice, the consumer must consider that if enrollment is postponed, then later enrollment is possible, but only with a permanent premium penalty equal to one percent of the average national premium for each month past the initial date of eligibility. Thus, an individual who is first eligible in January 2007 and delayed enrollment until September 2009 when the average national premium was $\$ 30$ per month would face for the remainder of life a premium penalty of $\$ 6$ per month, 20 percent of $\$ 30$. Then, early enrollment has option value even if not justified by current expected benefits. Second, in choosing a sponsor and plan for the year, the consumer should 
consider the risk of various medical events during the year, and the therapies and prices in the formulary of each plan.

There is little scientific information on the dynamics of health that interpreters can use to help consumers form rational expectations of health risks. Most of the information supplied to consumers, including the decision-making tools provided by the government, tacitly assume that a consumer's current health and drug needs will remain the same into the indefinite future. Heiss et al. (2007) find that there is in fact considerable persistence in drug bills, with 2005 and 2006 RPS pharmacy bills correlated 0.61. However, the underlying stochastic process is better described by a hidden Markov model with a relatively persistent latent health state than by a simple first-order Markov model, and mortality risk is an important aspect of the dynamics. The question for this market is whether consumers can overcome their own behavioral tendencies to behave myopically in an environment where the myopic attributes of plans are publicized and information on dynamic consequences is missing or ambiguous.

To examine dynamic rationality, Heiss et al. (2007) estimate a (hidden Markov) stochastic model of future pharmacy bills, given current health status, and examine the optimal enrollment decision for risk-neutral consumers with rational expectations. This determines a dynamic stochastic programming problem that is solved by backward recursion, and used to simulate optimally controlled health and drug use dynamics for each RPS respondent. We then compare observed and optimal enrollment choices. These calculations assume that consumers enroll in the Standard plan; joint modeling of enrollment and plan choice is a topic for future research.

It is possible for a number of reasons that our dynamic optimization might misstate the problem solved by a rational consumer - our stochastic model for health may be misspecified, the consumer may be risk-adverse, and we use a "market" discount rate that may give the future more weight than the subjective discount rate actually used. On the whole, these factors will induce higher enrollment rates than our model for dynamic rationality, so that the results of our model are a reasonable lower bound on those expected from fully rational consumers.

Table 3 compares actual enrollment decisions of 653 RPS deciders with the choices that would be either myopically optimal (e.g., maximize current expected net benefit) or dynamically optimal (e.g., maximize expected present value of net benefit). The diagonal percentages in bold are choices consistent with the myopic or dynamic optimality criterion, respectively, and the off-diagonal percentages are inconsistent choices. Then, 79.5 percent of active deciders make choices consistent with the myopic criterion, and 84.9 make decisions consistent with the dynamic criterion. There is a core of 8.4 percent of active deciders who 
fail to enroll even though it is myopically optimal for them to do so. Because enrollment is dynamically optimal for most, a slightly larger 13.6 percent fail to enroll when it is dynamically optimal, and only one percent enroll when it is not dynamically optimal. Enrollees have higher current and total net benefits from enrollment than do non-enrollees. Note that future net benefits are lower on average for enrollees than for non-enrollees. This is because enrollees are sicker and use more drugs than non-enrollees, and are not expected to live as long. An econometric analysis of factors entering enrollment decisions indicates that myopic behavior dominates. Future risk factors and the option value of avoiding the premium penalty appear to be heavily discounted or ignored.

Table 3: Actual vs. Optimal Enrollment of Active Deciders

\begin{tabular}{|c|c|c|c|c|c|c|c|c|}
\hline \multirow{3}{*}{$\begin{array}{l}\text { Actually } \\
\text { Enrolled? }\end{array}$} & \multirow[b]{3}{*}{ Total } & \multicolumn{3}{|c|}{ Myopically Optimal to Enroll? } & \multicolumn{4}{|c|}{ Dynamically Optimal to Enroll? } \\
\hline & & & & $\begin{array}{l}\text { Expected } \\
\text { Net Benefit }\end{array}$ & & & $\begin{array}{r}\text { Expec } \\
\text { Ber }\end{array}$ & $\begin{array}{l}\mathrm{Net} \\
\text { fit }\end{array}$ \\
\hline & & Yes & No & Current & Yes & No & Future & Total \\
\hline Yes & $85.5 \%$ & $73.3 \%$ & $12.1 \%$ & $\$ 1,217$ & $83.9 \%$ & $1.5 \%$ & $\$ 295$ & $\$ 1,510$ \\
\hline No & $14.5 \%$ & $8.4 \%$ & $6.2 \%$ & $\$ 523$ & $13.6 \%$ & $1.0 \%$ & $\$ 324$ & $\$ 845$ \\
\hline Total & $100.0 \%$ & $81.7 \%$ & $18.3 \%$ & $\$ 1,116$ & $97.5 \%$ & $2.5 \%$ & $\$ 299$ & $\$ 1,413$ \\
\hline
\end{tabular}

Switching behavior by enrollees in 2007 gives further evidence on dynamic optimality. In RPS, 62 percent of active deciders did not consider switching, 18.4 percent considered switching but did not, and 10.7 percent actually switched. The primary reasons for switching were that the previous plan was no longer offered or had a premium increase, or had unsatisfactory deductible or gap coverage. There was not widespread search for lower premiums, and there appears to be substantial "lock-in" to current plan. If insurers were unconstrained on pricing, this consumer behavior would give them incentives to offer low "teaser" rates or bonuses to new enrollees, and establish high premiums for current enrollees. Government regulation largely prevents this, but there have been reports of aggressive and deceptive marketing to induce switching. 


\section{Conclusions}

In the following paragraphs we summarize our findings on the ability of consumers to look after themselves in the Medicare Part D prescription drug insurance market in the United States, comment on the effectiveness of the design of this market for inducing efficient resource allocation, and finally comment on the lessons that can be drawn from this market about the practicality of Consumer Directed Health Care as a method for controlling health care costs.

Score Card for Consumers. Overall, a large majority of consumers introduced to the Medicare Part D market for prescription drug coverage faced immediate gains from enrollment, and most of these did enroll. A minority of 8.4 percent of active deciders failed to enroll in contradiction to their immediate selfinterest. This behavior was concentrated among people with low education, low but non-poverty income, and moderate current drug use. Choices among sponsors and plans was noisy, but cheap plans were favored. Dynamic optimization is weak - consumers appear to fail to predict changes in health status, and give insufficient weight to the option value of enrolling now in order to have affordable coverage when it is needed. There appears to be strong "lockin", with low rates of plan switching in the face of substantial changes in premiums and plan features.

The picture that emerges is that most elderly consumers faced with high-stakes decisions, even among novel complex products, make choices that are reasonably consistent with their self-interest. However, there are a minority that do not. Further, choices are tilted toward alternatives that appear best in terms of easily compared attributes, such as plans with low premiums or plans that offer the largest immediate benefits. Future risks and consequences of choices are given low weight, making consumers vulnerable to products that look good now but have poor prospects. This vulnerability is increased by inertia - once choices are made, many consumers are inattentive and do not evaluate or respond to switching opportunities.

Score Card for the Part D Market. The design and management of the Part D market by Medicare has been largely successful in standardizing the products offered in the market so that there were no bad choices, neutralizing adverse selection so that incentives to sponsors to screen enrollees were minimal, and fostering competition among sponsors that has led to lower than expected premiums and more aggressive use of generic drugs. The Medicare outreach program to encourage enrollment was largely successful, and overall 92.6 of eligible 
seniors age 65+ enrolled in Part D or a comparable drug insurance program, and an even higher percentage of heavy current drug users who stood to benefit immediately. However, there are some market features that threaten its success. The market has rapidly become quite concentrated, dominated by three insurers (Humana, United Healthcare/AARP, and Anthem Blue Cross). These companies may have sufficient market power to influence premiums and formularies, despite the moderating influence of a fringe of small insurers. Extended plans, whose extra features such as gap coverage are not subsidized, appear to be affected by adverse selection, with rapidly rising premiums and reduced coverage. Plans with full gap coverage of branded and generic drugs are now essentially extinct, and plans with gap coverage of generic drugs are now nearly priced out of the market and appear to be in a death spiral, purchased by a shrinking number of consumers with higher claims.

Some of the apparent tactical success of the Part D market in achieving high enrollments and low premiums may be the result of a feature that reduces the efficiency of resource allocation and burdens sicker beneficiaries and taxpayers. The regulation of sponsors requires that beneficiaries in the gap, and government catastrophic reinsurance, face the same drug prices as those negotiated between the sponsor and pharmaceutical companies and paid by the sponsor. However, the negotiations between pharmaceutical companies and sponsors are not regulated, and rebates or kickbacks from the pharmaceutical companies to the sponsors are not forbidden. This creates an incentive for the pharmaceutical companies and sponsors to leave list or stated prices of drugs high, and instead negotiate rebates that are not linked to specific drugs. This allows sponsors to reduce premiums to attract enrollees, and reduces Medicare's direct subsidy, but this is more than made up through increased reinsurance costs. On average, enrollees pay more, with the heaviest burden falling on those who are in the gap at the end of the year, and gains to a minority of beneficiaries who use few drugs. Currently, information on rebates is hidden from the public by "commercial privacy" rules, and this source of market inefficiency is unlikely to be corrected as long as these kickbacks remain hidden.

Lessons for Consumer Directed Health Care. Most, but not all, consumers are able to make health care choices consistent with their self-interest, even in the face of novel, complex, ambiguous alternatives. However, certain predictable irrationalities appear - excessive discounting of future health risks, and too much concentration on dimensions that allow easy comparisons, such as current cost and immediate net benefit. Some consumers are inattentive, particularly when prior choices or circumstances identify a default "Status quo" alternative. 
These behavioral shortcomings imply that some degree of paternalism is essential if Consumer Directed Health Care is to allocate resources satisfactorily. Health care markets need to be regulated to keep out bad, deceptive products, particularly those that offer "teaser" current benefits but poor longer-run benefits. Consumers need good comparative information on products, and they need to have this information brought to their attention. Consumers appear to underestimate the probabilities of future health events, or anticipate the resulting disutility, and as a result they systematically underspend on preventative or chronic care. Social optimality will require that these services be subsidized, or choices regarding them be framed, to induce lifetime utility-maximizing levels of utilization.

Perhaps the most important observation from the Part D experience is that health care markets involve information asymmetries that can cause market failure or wasteful sorting due to adverse selection and moral hazard, but careful design and monitoring of risk adjustment formulas, "must carry" provisions that reduce incentives for sponsors to engage in costly screening of consumers on observable dimensions, and subsidies that make coverage attractive to the healthy, can be used to make these markets work. An important caution is that health care markets have to operate in the face of private incentives for actions that threaten their stability and efficiency, and constant regulatory vigilance is required to meet new attacks and keep them on track.

A final question is whether, in light of the limits and predictable irrationalities of consumers, and the constant pressure from information asymmetries to drive health care markets off track, the game is worth the candle. If these markets are so difficult to design and operate, and require such careful regulation even when consumer choices are sending the right price signals, wouldn't centralized resource allocation through a government single payer/single provider program be more attractive? We believe the answer is that the same difficult problems of aligning incentives, signaling needs, and achieving efficient resource allocation will still be present in any centralized health care system. In the end, a well-run single provider system or a well-designed market system are going to have to confront and solve similar problems. 


\section{References}

Bach, P. B., and M. B. McClellan (2005), "A Prescription of a Modern Medicare Program”, New England Journal of Medicine, 353, pp. 2733-2735.

Bach, P. B., and M. B. McClellan (2006), "The First Months of the Prescription-Drug Benefit: A Cms Update”, New England Journal of Medicine, 354, pp. 2312-2314.

Beeuwhes Buntin, Melinda, Cheryl Damberg, Amelia Haviland, Nicole Lurie, Kanika Kapur, and M. Susan Marquis (2005), "Consumer Directed Health Plans: Implications for Health Care Quality and Cost”, California Health Care Foundation, RAND Corp.

Davis, Karen (2004), "Will Consumer-Directed Health Care Improve System Performance?" Commonwealth Fund Issue Brief.

Heiss, Florian, Daniel McFadden, and Joachim Winter (2007), "Mind the Gap! Consumer Perceptions and Choices of Medicare Part D Prescription Drug Plans", NBER Working Paper 13627.

Heiss, Florian, Daniel McFadden, and Joachim Winter (2006), "Who failed to enroll in Medicare Part D, and why? Early Results", Health Affairs, 25, pp.w344-w354.

Herrick, D. (2005), "Consumer Driven Health Care: The Changing Role of the Patient", National Center for Policy Analysis, policy report.

Joyce, G. F., J. J. Escarce, M. D. Solomon, and D. P. Goldman (2002), "Employer Drug Benefit Plans and Spending on Prescription Drugs", Journal of the American Medical Association, 288(14), pp. 1733-1739.

KRC Research (2007), "Seniors' Opinions about Medicare Rx: Second Year Update", www.krcresearch.com.

McFadden, Daniel (2006), "Free Markets and Fettered Consumers", American Economic Review, 96(1), pp. 5-29.

Medpac (2006), "Part D Payment System", www.medpac.gov.

Perry, M., A. Dulio, and J. Cubanski (2006), "Voices of Beneficiaries: Medicare Part D Insights and Observations One Year Later", Kaiser Family Foundation report.

Robst, John, Jesse M. Levy, and Melvin J. Ingber (2007), "Diagnosis-Based Risk Adjustment for Medicare Prescription Drug Plan Payments", Health Care Financing Review, 28, pp. 15-30.

Winter, Joachim, R. Balza, F. Caro, Florian Heiss, B. Jun, R. Matzkin, and Daniel McFadden (2006), "Medicare Prescription Drug Coverage: Consumer Information and Preferences", Proceedings of the National Academy of Sciences of the United States of America, 103(20), pp.7929-7934. 


\section{SUMMARY}

In health care systems today, including those of Switzerland and the United States, participants do not necessarily see the big picture of lifetime health costs and quality of life, and in many systems consumers and providers lack the incentives to manage preventative and chronic care to minimize lifetime private and social health costs. Resource allocation problems induced by asymmetric information and misaligned incentives are exacerbated if consumers fail to have the acuity or perspective needed to make choices consistent with their self-interest when faced with complex health care choices with ambiguous future consequences. This paper examines rationality of consumers' health perceptions and choices using as a natural experiment the recent introduction in the United States of a highly subsidized market for prescription drug insurance, and draws lessons from this experiment on the practicality of "Consumer Directed Health Care" as an approach to achieving efficient allocation of health care resources by confronting consumers with the full marginal costs of the services they use. 